\title{
REPENSANDO A TUTELA DOS DIREITOS
}

\author{
Carlos Silveira Noronha ${ }^{1}$
}

\section{NOÇÕES INTRODUTÓRIAS}

O vocábulo "tutela" traduz a ideia de amparo, proteção, defesa, apoio e guarda, em sentido genérico. Sua origem etimológica está na palavra homógrafa do nominativo latino "tutela", genitivo "tutelae", tendo sido usada na acepção jurídica por Cícero, em "Pro Caecina". Com tal semântica, trasladou-se a expressão para a linguagem jurídica moderna, passando a significar, neste ramo do conhecimento científico, a proteção que a ordem jurídica se propõe a conferir às pessoas, aos bens e às relações que dela venham a necessitar para se resguardarem das ameaças de lesão ou para se recuperar de lesões efetivamente sofridas.

A ideia de tutela, em sentido amplo, resta substancial e formalmente amparada na própria estrutura do ordenamento jurídico que a contempla. Qualquer sistema jurídico positivo deve conter uma compleição capaz e bastante não só para satisfazer-se e efetivar-se como sistema definidor

1 Professor titular de Direito Civil no Curso de Pós-Graduação estricto sensu da Faculdade de Direito da UFRGS e no Curso de Direito, em nível de graduação, das Faculdades integradas São Judas Tadeu de Porto Alegre; mestre e doutor em Direito pela Universidade de São Paulo (USP).

2 Prof. Ernesto Faria - Dicionário Escolar Latino-Português, p. 1.028-1.029, 4. ed. Publicação do Departamento Nacional de Educação do Ministério da Educação, Rio de Janeiro, 1967. 
das condutas humanas na via do proceder retilíneo dos cidadãos que agem segundo o direito mas, também, como sistema instituidor dos instrumentos de proteção dessas condutas, quando, por efeito da falibilidade ou da descompostura do agir humano, venha o sistema descambar para o proceder negativo, pela via do ilícito ou do "tortus".

Na perspectiva ora examinada, é mister se tenha presente que, na visão jusfilosófica, direito e torto são noções interdependentes e complementares, porque o direito, pela sua condição de ciência do homem, "é essencialmente violável e existe por graça de sua violabilidade", aduzindo ainda os jusfilósofos que "não se pode conceber o Direito, senão em correlação com o seu contrário: o "torto". Houve mesmo quem sustentasse, no campo da investigação jurídico-filosófica, que a noção de "tortus" antecede a noção de "ius" .

Data maxima venia da singular autoridade desfrutada por Del Vecchio no campo da filosofia, parecenos ser mais consentânea, ao tratar-se do fenômeno jurídico, substituir-se a noção de tortus pela de ilícito, por significar esta a expressão que se contrapõe à de direito.

$\mathrm{E}$, assim que da noção de direito com a noção de tortus ou de ilícito resulta a construção de um sistema de tutelas protetoras dos direitos, seja para preveni-los ante a ameaça de sua desintegração ou destruição, seja para recuperá-los em face da lesão consumada pela descompostura de uma das partes, caracterizada no descumprimento do dever ou da obrigação relativamente ao direito da outra parte.

$\mathrm{Na}$ verdade, um sistema de tutelas, para tornar-se operante e efetivo, deve compartimentar-se e completar-se objetivamente, sem lacunas no ordenamento jurídico. E para alcançar esta operosidade e efetividade, mister se faz que o sistema de tutelas se encontre inteiramente positivado, definido e integrado no ordenamento estatal e revestido, obviamente, das características de generalidade, completude, bilateralidade, e, no seu modo de atuar, revestido de fatores tais como os da voluntariedade e da coercibilidade, quando esta última se tornar necessária.

Isto, porque, deve-se ter em vista que a sociedade, em sua totalidade, não é composta por uma coorte de seres angelicais, na qual não se contemplaria o erro ou o ilítico, não se descumpriria o dever e nem se teria a perspectiva de que tal poderia vir a ocorrer, mas, ao contrário, convivem no complexo social, ainda que em

3 DEL VECHIO, Giorgio. Lições de Filosofia do Direito. Tradução portuguesa de Antonio José Brandão, p. 39. Coimbra: Editora Armenio Amado, 1979. 
minoria, entes imperfeitos, falíveis e suscetíveis de erronias e ilicitudes nas mais variadas ações humanas. Por tais razões, torna-se necessária a instituição de uma ordem jurídica completa e eficaz, para definir regras de conduta, sustentar o equilíbrio das relações sociais, como também para estabelecer e assegurar um ordenado elenco de instrumentos de tutelas hábeis a prevenir ou reparar os males consequentes de desvios de condutas humanas, que venham a perturbar o ambiente social.

De fato, negar-se-ia a si próprio o ordenamento jurídico que se limitasse a reconhecer abstratamente uma universidade de direitos atribuíveis aos seus cidadãos e não se propusesse adotar um sistema de tutelas capazes de dar-lhes proteção. É que, em sentido lógico e em sentido material, a estrutura de qualquer ordenamento jurídico só resta completa com a interação de uma dualidade de instrumentos de tutelas que venha a confirmar o brocardo jurídico em voga, sempre presente na expressão: "ubi ius, ibi remedium". ${ }^{4}$

Desse modo, um ordenamento jurídico pode adquirir seu grau máximo de efetividade, quando formalmente editado e posto em vigor segundo as regras que regulam a sua fonte de produção e, bem assim, quando institui um sistema de tutelas adequadas e bastantes para realizar-se, efetivamente, pela via da espontaneidade do sujeito, no cumprimento do dever ou pela via da coerção estatal, quando falhar a primeira.

A tutela dos dirteitos, em sentido amplo, implica uma compreensão material e objetiva do complexo jurídico estatal instituído para oferecer proteção ao grande universo de direitos subjetivos de que são titulares os cidadãos nacionais, devendo salientar-se que as categorias jurídicas que formam o sistema de tutelas vêm se constituindo histórica e necessariamente um dos relevantes papéis a cargo do Estado.

No entanto, a noção de direito individual vem cedendo espaço à noção social, em decorrência da elevação dos direitos sociais à categoria de $d i$ reitos de segunda geração $o^{5}$ em que a doutrina moderna propõe a substituição do termo geração pelo de dimensão $^{6}$, na classe das chamadas

4 DI MAJO, Adolfo. La Tutella Civile dei Diritti. p. 57-58. Milano: Ed. Giuffrè, 1987. 5 PELLOUX, Robert. Vrais et Faux de 1'Homme - Problèmes de Definition et de classification. In: Revue de Science Politique em France et à l'étranger, n. I, p. 54 e note 8. 6 BOBBIO, Norberto. Bobbio e a Filosofia dos Juristas. Porto Alegre: Sérgio Fabris Editor, 1994; BONAVIDES, Paulo. Curso de Direito Constitucional. p. 571-572. São Paulo: Edição Malheiros, 2009; OLIVEIRA JUNIOR, José Alcebíades de. Estado e 
liberdades públicas ou dos direitos fundamentais ${ }^{7} \mathrm{e}$, bem assim, devido às influências sofridas com o surgimento da concepção social acerca dos papéis do Estado na consecução do bem comum, em termos modernos. E, notadamente, a partir do segundo quartel do século $X X$, vêm de destacando do direito subjetivo clássico os chamados direitos supraindividuais (coletivos e difusos), bem como vem sendo proclamada por certa corrente de opinião a categoria dos interesses legítimos.

Os chamados interesses legítimos constituem um novo fenômeno que está sendo construido pela ciência jurídica como resultado da coexistência entre o interesse público e o interesse privado, com o escopo de abrigar pretensões reflexas do sujeito privado toda vez que o poder público exercitar o interesse social em conformidade com as regras de conduta pública estabelecidas pelo ordenamento jurídico.

Tal posição não se identifica perfeitamente com a de direito subjetivo, no âmbito do direito substancial, que atribui ao indivíduo "um bem da vida", mas se compraz com a figuração de um poder de invocar um tipo de controle do ordenamento acerca do uso do poder público como se o particular fosse investido da função pública conferida no ordenamento pátrio ao Ministério Público de fazer respeitar a lei nos atos praticados pela pública administração. O interesse legítimo poderia ser concebido quase como uma mera ação deferida ao particular para controlar a prática de atos estatais, na visão de Chiovenda.

A título de exemplo, pode-se afirmar que o tipo de interesse privado que goza de maior proteção é o do dominus na relação de domínio, que é absoluto e incondicionado e se produz erga omnes. Pois bem, o interesse do proprietário não pode mais definir-se como direito subjetivo absoluto e incondicionado, sempre que diante dele subsistir o poder do ente público de sacrificar o bem objeto da propriedade, porque assim o exige o interesse social, por exemplo, a deliberação pública de construção de uma estrada ou a construção de uma escola, no solo de propriedade privada ${ }^{8}$.

Diz-se que, nesse caso, o interesse do dominus é levado a ceder em face do interesse público, que exige a

Edicácia dos Direitos Fundamentais. In: Revista do Direito da Unise. n. 11, p. 52, Santa Cruz do Sul, 1999.

7 FERREIRA FILHO, Manoel Gonçalves; GRINOVER, Ada Pellegrini; FERRAZ, Ana Cândida. Liberdades Públicas. p. 45-72. São Paulo: Edição Saraiva, 1978.

8 É de se notar que o direito de propriedade está delimitado não só nos ordenamentos socialistas, como nos do mundo ocidental, onde, a par do seu reconhecimento, é 
realização da obra pública. Não se trata aqui de respaldar o argumento de que a tutela se lança para resguardar o interesse público, pois dúvidas não restam de que o interesse privado pode ser livremente sacrificado pelo interesse público.

Todavia, nao é isso que se quer dizer, mas sim que, nesse tipo de relação jurídica, entre o público e o privado, resta um resíduo de tutela de tipo diverso daquela que se opera nas relações entre particulares. Sustenta-se, que tal tutela tem caráter condicionado e reflexo. Na realidade, o particular, apesar de sua posição de submissão ao interesse dominador, tem ainda possibilidade de invocar tal remédio toda vez que o sujeito público deixe de exercitar corretamente, na conformidade da lei, o poder supremacial que lhe é conferido, figurando essa proteção especial como remédio contra o mau ou incorreto uso pelo poder público.

Poderá, assim, o proprietário lamentar-se que o poder expropriante não tenha sido exercitado para o fim ou escopo público destinado pelas leis do Estado, mas instrumentalizado para outros fins. Em tal hipótese, costuma-se dizer que o particular investe-se na titularidade de um in- teresse legítimo e não de um direito subjetivo. A expressão não é muito comum na literatura jurídica, mas já figura em algumas Cartas Constitucionais modernas, tais como na Constituição italiana de 1948 (artigo 24) e na Constituição portuguesa de 1976 (artigo 209). A atual Constituição brasileira de 1988, embora não contenha especificamente a expressão interesse legítimo, em várias passagens refere-se a direitos e interesses, quando cuida de temas pertinentes às garantias fundamentais (art. 59, incisos XXXII, XXXV, LX e LXX, $\underline{b}$ ); aos sindicatos $\left(\operatorname{art} .8^{\circ}, \mathrm{III}\right)$; à proteção da ecologia (art. 129, III); aos índios (arts . 129, V e 232). Já o Código de Defesa do Consumidor, editado pela Lei $\mathrm{n}^{\circ} 8.078 / 90$, confere extenso elenco de meios de tutela para os interesses difusos, coletivos e individuais homogêneos. O mesmo ocorre com a Lei ${ }^{\circ}$ $7.347 / 85$, que disciplina a ação civil pública, para proteger os interesses difusos pertinentes ao meio ambiente e aos consumidores.

As dificuldades acerca das distinções e soluções do problema em análise tornam-se menos severas quando o vislumbramos pelo plano da tutela. A diferença entre direitos subjetivos e

salientada sua função social. Assim, na França (artigo $17^{\circ}$ da Declaração dos Direitos do Homem e do Cidadão de 26.08.1789, incorporado ao preâmbulo da Constituição de 1946 e ratificado pelo Estatuto de 1958); Na Itália (Constituição atual, artigo 42); na Espanha (Constituição de 1978, artigo 33); em Portugal (Constituição de 1976, artigo $62^{\circ}$ ). A Constituição brasileira de 1988 estabelece a função social das propriedades urbana e rústica do Título VII, Capítulos II e III, artigos 182 a 191. 
interesses legítimos não se refere ao interesse substancial do sujeito privado, que continua a ser o mesmo - v.g., o interesse do proprietário é o de excluir qualquer ingerência sobre a coisa própria, mas diz respeito ao modo e à forma de proteção.

Nas relações privadas há uma forma de tutela incondicionada, que é outorgada ao titular do interesse reconhecido pela lei material, seja no âmbito dos direitos reais ou pessoais, ao passo que nas relações de direito público, a ordem jurídica confere ao indivíduo não o poder de pretender em concreto "um bem da vida" nos exemplos referidos, quanto ao respeito ao direito de propriedade, ou à vitória em um concurso, ou a obtenção de licença edilícia, mas o respeito às regras jurídicas que disciplinam a atuação do poder público, para, no caso de seu descumprimento, chegar-se à anulação do ato ilegítimo. E o particular não invoca dita observância da lei animado por mero motivo altruístico, mas porque espera que também o seu interesse material venha a ser satisfeito ou de qualquer modo salvaguardado, eis que, a anulação do processo expropriativo revigora o seu direito de propriedade e, com a renovação do concurso, pode o candidato prejudicado tornar-se vencedor do mesmo e recuperar o prejuízo sofrido.

Mas tal construção pode ser acolhida porque não se trata de um inte- resse material diverso, mas de uma forma distinta de relevância deste e, em consequência, de tutela, atribuída ao particular quando o interesse deste coexiste com o interesse público. É nessa forma de coexistência que se deve colocar a característica nuclear de tal fenômeno. Mas a dita coexistência não pode ser assim considerada quando se venha a conceber simplesmente a presença de um interesse público dominador perante um interesse privado dominado, cuja relevância só se projeta acidentaliter, pois neste caso não se gera o interesse legítimo. É preciso que a coexistência entre um e outro interesse se projete essencialiter, para que deflua das normas atributivas do poder público em confluência com o interesse privado. É na forma de coexistência entre os dois interesses que se instala o quid novi do fenômeno.

Não existe um modelo homogêneo de interesses legítimos, como soe acontecer com os paradigmas do direito subjetivo. Aqueles se apresentam na arena jurídica com grande diversidade, mas tornam-se identificáveis por meio da coexistência de caráter essencial entre o interesse privado e o público.

É nessa perspectiva que alguns ordenamentos jurídicos e a doutrina internacional vêm sendo construídos à tutela dos interesses legítimos. ${ }^{9}$ 
É oportuno seja, neste passo salientado, que a doutrina dos interesses legítimos tem destaque no sistema italiano, onde existe duplicidade de funções jurisdicionais, consubstanciadas em uma jurisdição administrativa, esta realizada pela via do contencioso administrativo. Resulta, dessa duplicidade de jurisdições, uma tutela civil e uma tutela administrativa. Segundo essa doutrina, como já se disse anteriormente, os chamados interesses legítimos constituem um novo fenômeno que está sendo construído pela ciência jurídica como resultado da coexistência entre o interesse público e o interesse privado, com o escopo de abrigar pretensões reflexas do sujeito privado toda vez que o poder público exercitar o interesse social em conformidade com as regras de conduta pública estabelecidas pelo ordenamento jurídico. Assim, em realidade, para a doutrina italiana os interesses legítimos comportam-se, naquele sistema, como direitos subjetivos refle$x o s$, para a proteção dos quais é reservada uma tutela residual ${ }^{10}$.
Todavia, deve ser observado que, a par direito pátrio não contemplar o contencioso administrativo do sistema italiano, registra-se entre nós a singularidade da proteção conferida ao direito subjetivo de qualquer das partes intervenientes na relação jurídica, e, ainda, que nesta convivam interesse privado e interesse público reflexo, a solução desta se opera exclusivamente pela tutela judicial necessária, porque afastada a tutela substancial, em razão da presença do interesse público prevalente e indisponível, por consequência.

De tal modo, não se vislumbra proveito na distinção doutrinária entre as categorias de direito subjetivo e interesse legítimo no direito brasileiro. E, assim, autores nacionais, como Calmon de Passos, repelem esta distinção, entendendo-a desautorizada pelo sistema nacional, quando refere: "Trazer-se para o direito brasileiro categorias já sem funcionalidade como a dos interesses legítimos, para colocá-los ao lado dos direitos subjetivos, ou pretender excluir os inte-

Alemanha: VON THUR, V. A. Teoria General Del Derecho Alemán. Trad. esp., V. I, p.73 e segs.; em Portugal: COLAÇO ANTUNES, Luis Filipe. A Tutela dos Interesses Difusos em Direito Administrativo. p. 55-61. Coimbra: Ed. Livraria Almedina, 1989; e, ainda, MELO FRANCO, João; ANTUNES MARTINS, Herlander. Conceitos e Princípios Jurídicos. p. 403. Coimbra: Livraria Almedina, 1983; no Brasil, ver, entre outros, GOMES, Orlando. Introdução do Direito Civil. n. 73, p. 142-143. Riode Janeiro: Edição Forense, 1999.

10 DI MAIO, Adolfo. La Tutela Civile dei Diritti. Milano: Ed. Giuffrè, 1987; MONTESANO, Luigi. La Tutela Giurisdizionali dei Diritti. § 19, p. 40-43. Bari: Cacucci Editora, 1981. 
resses transinviduais da categoria dos direitos subjetivos é insistir numa visão do direito do Estado, da organização política e da sociedade, já ultrapassadas ${ }^{11}$.

\section{DA BIPOLARIZAÇÃO DO SISTEMA DE TUTELA DOS DIREITOS}

Como se viu, a noção de tutela, abraçada pelo Estado moderno, abriga um elenco de remédios ou de instrumentos estabelecidos, valorados e reconhecidos pelo respectivo sistema jurídico como adequado e satisfatório para amparar os direitos de que são titulares seus súditos, nas relações travadas no comércio jurídico e, bem assim, a instituição de um elenco de estilos e formas de cumprimento do dever ou da obrigação pelo outro interveniente no negócio jurídico. E tais instrumentos se realizam mediante dois sistemas de tutela distintos, ou seja, pela operosidade da tutela substancial, que se realiza no âmbito do direito ma- terial, ou da tutela judicial, que é disciplinada e se perfaz no concerto do direito processual. Assim, a tutela jurídica operada no horizonte da justiça civil realiza-se em dois planos distintos: no plano substancial, que se realiza espontaneamente, mediante o cumprimento do dever ou da obrigação, pelo obrigado, ou ainda, mediante a composição negociada entre as partes intervenientes no ato ou no negócio jurídico, ou em derradeiro, insubsistente esta, no plano judicial, realizado na área e por efeito da coação estatal, chamada a agir, por meio do processo judicial, operante nas situações patológicas que recaem sobre a relação jurídica material pelo descumprimento do dever ou da obrigação, pelo obrigado. Registra-se, assim, uma abrangência bipolarizada do sistema de tutela dos direitos. A primeira, também denominada mais popularmente extrajudicial ou extraprocessual e, a segunda, pode ser, com menor rigor técnico, denominada também judicial ou processual.

A tutela substancial nasce e se realiza ordinariamente inclusa no

11 A posição do citado autor nacional, contrária à distinção entre "direito" e "interesse" é extensiva aos chamados "interesses transindividuais". Sobre tal distinção Calmon de Passos, ainda se manifesta: "A dualidade de terminologia (interesses, no transindividual; direito, no individual) é de todo desautorizada, apenas traduzindo o remanescente conservador (mesmo inconsciente) dos que ainda não lograram se libertar da estreita cela em que foi aprisionada a noção clássica de direito subjetivo" CALMON DE PASSOS, J.J. In: Mandado de Segurança Coletivo, Mandado de Injunção, Habeas Data. p. 10-11. Rio de Janeiro: Edição Forense, 1989. 
contexto da relação material, de modo que, formada concretamente a relação jurídica, nela já se contém um corpo de instrumentos tutelares destinado a oferecer-lhe proteção, para impedir a ocorrência de situações adversas que venham a obstaculizar ou impedir a realização dos seus efeitos jurídicos, quais sejam a satisfação do direito do sujeito titular e o correspectivo cumprimento do dever pelo obrigado.

Assim, em senso comum, tutelar um direito no âmbito do direito material, significa implementar o amparo que naturalmente lhe advém da norma de conduta positivada no sistema jurídico e dos princípios vetores que the informam genericamente. E, deste modo, a tutela substancial, que se opera voluntária e espontaneamente, projeta-se mediante a observância das regras de conduta estabelecidas para a convivência harmônica de quantos participam do ambiente comunitário, na medida em que essas regras são editadas pelo Estado para reger os destinos sociojurídicos dos indivíduos que a elas se submetem, as acolhem, as observam integralmente com naturalidade e espontaneidade, atendendo a mensagem de cooperação e boa-vontade que se insere nos escopos social e político de harmonia e concórdia, como afluentes do macro-escopo do bem comum, papel do Estado moderno.

Com efeito, deve ser observado que na atuação da tutela substancial registra-se uma precedência ou an- terioridade em relação a atuação da tutela judicial, caracterizando-se tal precedência como lógica e necessária. E essa precedência da primeira em relação à segunda revela-se lógica pelo fato de os respectivos instrumentos de tutela dessa ordem se conferirem naturalmente no próprio corpo da relação jurídica a ser protegida, atuando, assim, os referidos instrumentos tutelares automaticamente, no momento em que a dita relação vier a carecer de proteção.

Caracteriza-se, ainda, como necessária essa precedência da tutela substancial em relação à judicial, porque a provocação da jurisdição, mediante a ação e a instauração do respectivo processo, exige interesse de agir da parte autora e este não se dá enquanto não se esgotam todos os meios suasórios da pretensão do titular do direito perante o obrigado, ou seja, não podem ser ativados os remédios judiciais de tutela enquanto não se esgotarem ou não se mostrarem insuficientes ou inábeis os instrumentos substanciais de proteção. E assim o é, porque inobservada essa exigência, o autor da ação judicial seria considerado carecedor da ação, por inexistência de interesse de agir como prescreve o artigo 267, inciso VI da lei processual.

Outra característica da tutela substancial é a de ser originária, pelo fato de se realizar desde logo, imediatamente após tornar-se exigível o 
direito do respectivo titular, constituindo-se, assim, esse tipo de tutela, o modo mais direto, mais genuíno e mais expedido do cumprimento do dever pelo obrigado, situação essa que se consubstancia no primeiro e relevante papel do cidadão perante $o$ Estado que the oferece proteção social, política e jurídica em geral.

Reversamente, tal não ocorre com a tutela judicial, na qual o instrumento protetor do direito lesionado nasce externamente e extraordinariamente em outra relação jurídica, a relação processual, distinta da relação material tutelada, a qual se forma em face do descumprimento do dever ou da obrigação, pelo obrigado, a partir do exercício da pretensão de direito material e da ação judicial pelo titular do direito descumprido.

Assim, em realidade, a própria composição e inteireza de qualquer sistema normativo de tutelas deve estruturar-se, necessariamente, por essa forma bipolarizada dos canais de tutela substancial e judicial, com o escopo de oferecer efetividade e segurança quanto ao cumprimento espontâneo, negociado ou coativo das relações jurídicas travadas entre os cidadãos nacionais. $E$ tal sistema tutelar dos direitos e, correspectivamente, o cumprimento dos deveres, por um e outro participante do ato ou negócio jurídico, a par de exercer seu relevante desiderato de propiciar a justeza de comportamentos das partes entre si, ainda tem o condão de sua indispensabilidade, na ordem estatal, para compor as soluções suasórias ou contrariadas entre os sujeitos delas participantes. É de notar-se que sem essa duplicidade de meios de tutelas, restar-se-ia inobservada ou insatisfeita a efetividade da ordem jurídica estatal.

Destarte, como já foi anteriormente observado neste trabalho doutrinário, o primeiro canal desse complexo tutelar dos direitos a ser implementado, é o da tutela substancial, que nesta circunstância se caracteriza como tutela originária, por instrumentar-se no complexo da própria relação jurídica material, porque é nesta que se instala originariamente a primeira sede da consciência de dever a ser cumprido por uma das partes perante a outra, e tal ocorre na exata oportunidade temporal que for estabelecida, cuja satisfação deverá operar-se por meio da tutela substancial direta ou indireta. E só na hipótese da superveniência de alguma circunstância que venha a modificar e afetar a consciência de dever inicialmente concebida por uma das partes, é que é invocada pelo prejudicado a tutela judicial, operada mediante a atuação coercitiva que a ordem jurídica atribue ao Estado, em caráter de substituição à substancial, por haver esta se tornado insubsistente, em face da alteração conceptiva que sobreveio na mente do obrigado a respeito do cumprimento do dever. 
Desse modo, a tutela judicial assume o caráter de tutela substituti$v a$, na impossibilidade de operar-se a tutela substancial originariamente instrumentada na própria relação jurídica material, seja quando lesionado ou ameaçado de lesão o bem jurídico disputado pelas partes, ou impossibilitada a composição amigável pelo desentendimento dos intervenientes na relação jurídica questionada.

Assim sendo, pelo modo e pela oportunidade de sua atuação para dar solução ao ato ou negócio jurídico, seja qual for a sua natureza, a tutela judicial exerce a função de tutela derivada, consequencial ao insucesso da tutela substancial, quando esta deixar de atuar por inviabilidade ou por insuficiência de seus instrumentos estruturais, persuasivos e exortativos do obrigado a cumprir o dever ou a obrigação, ajustados na formação da relação negocial. É diante de tais contingências que a tutela judicial deve ser provocada mediante o exercício da pretensão, pelo titular, do direito descumprido pelo obrigado, que, então, se opera pela atuação coercitiva do Estado-Juiz.

De tal modo, é de se inteligir que a expressiva maioria das relações e situações jurídicas são implementadas e cumpridas em razão da consciência de dever e o de proceder correto restarem no seio da sociedade que emerge da formação ético-moral residente na generalidade do complexo social, subsistindo circunstancialmente e em caráter excepcional o erro e a ilicitude, o que autoriza a conclusão de que a solução das relações jurídicas é operada por meio da tutela substancial, surgindo como exceção a tutela judicial, embora, também, não se ignore que atualmente os órgãos judiciários labutam assoberbados por cópia quase invencível de processos a serem julgados.

Atua, pois, a tutela judicial que se opera no âmbito do direito processual, nas situações patológicas da relação de direito material, quando esta, por inaptidão ou por sua carência de meios coercitivos, deixar de implementar, por seus próprios instrumentos de tutela, situações de desconforto originadas por desentendimentos das partes. É diante dessa perspectiva a manifestação sempre precisa de Pontes de Miranda: "O processo não é mais do que o corretivo da imperfeita realização automática do direito objetivo" $"$.

Através do compartilhamento ou da bipolarização desses dois canais de tutela, abrangentes dos dois setores da ordem jurídica, resta a mesma

12 PONTES DE MIRANDA. Francisco Cavalcante. Comentários ao Código de Processo Civil. Tomo I, p. 100. Rio de Janeiro: Edição Forense, 1973. 
armada dos instrumentos necessários e adequados para alcançar sua concreta, efetiva e plena realização. É nesse sentido a doutrina de Dinamarco: "Mostre-se a ideia da tutela como meio de promover a efetividade do ordenamento jurídico ${ }^{13}$ ". Referência especial, nesse particular, merece o Código Civil italiano, que dedica o Livro VI, integrado pelos artigos 2.643 a 2.969 , para a disciplina "Della tutela dei diritti", sede em que distingue as duas espécies de tutela. A substancial, nos artigos 2.643-2.903, quando tratam da transcrição, das provas, da responsabilidade patrimonial (privilégios, penhor, hipoteca, dos meios de conservação da garantia patrimonial) e, nos artigos 2.934-2.969, que tratam da prescrição e da decadência; e a tutela jurisdicional, nos artigos 2.907-2.933 que tratam da execução forçada, da expropriação, do penhor, da venda forçada. Essas disposições contidas na codificação civil italiana dão o testemunho de que naquele ordenamento jurídico o sistema de tutelas dos direitos civis realiza-se nos dois terrenos: no substancial e no jurisdicional ${ }^{14}$.

Ainda que no sistema nacional as referências prescritas nos artigos
2.907-2.933 do Código Civil italiano não sejam, toda elas, consideradas jurisdicionais pelo direito pátrio, o exemplo da divisão de tutelas em substanciais e jurisdicionais pelo direito peninsular, visando a proteção dos direitos dos seus cidadãos, vem demonstrar que também em legislações alienígenas esse sistema dual de tutela dos direitos é estruturado e aplicado.

No sistema nacional, como se tem demonstrado, o sistema de tutela dos direitos congemina-se e se compartimenta nas duas vias de tutela examinadas, a tutela substancial e a tutela judicial, esta regulada expressamente no sistema e classificada segundo a natureza do bem jurídico do seu titular, cuja preservação seja por este reclamada, realizando-se pelo exercício da função coercitiva do estado-juiz.

A tutela substancial, por outro lado, não se encontra nominada, nem explicitamente disciplinada na lei nacional, mas os instrumentos próprios e adequados para oferecer proteção aos direitos do cidadão brasileiro encontram-se implicitamente presentes no contexto do nosso sistema e se praticam cotidianamente, tanto na persecução do cumprimento espontâneo do

13 DINAMARCO, Cândido Rangel. "Tutela jurisdicional”. In: Séparata da Revista Forense. V. 334, p. 25. Rio de Janeiro: Cia. Editora Forense.

14 Itália. Ver: Codice Civile e Leggi collegate. Libro Sesto Della Tutela dei Diritti, p. 446-491. Bologna: Ed. Zanichelli, 2007. 
dever ou da obrigação, pelo obrigado, por meio da tutela substancial direta, quanto na efetivação da tutela indireta em que o procedimento tutelar se opera mediante a colaboração do sujeito titular do direito, ou sujeito ativo, em acordo com o obrigado, ou sujeito passivo.

E essa atuação bipolarizada dos dois tipos de tutela projeta-se no direito nacional tanto mais relevante e até indispensável para compor o nosso sistema tutelar de direitos, quando se tem a percepção de que, sem essa duplicidade de instrumentos tutelares, restaria inobservada ou insatisfeita a efetividade da ordem jurídica nacional.

\section{DA RELEVÂNCIA DA TUTELA SUBSTANCIAL}

Como referido precedentemente, a tutela substancial em sentido amplo "lato sensu", divide-se em tutela substancial "stricto sensu", subdividindose esta em duas modalidades paralelas da tutela direta e da tutela indireta, que se congeminam, se coordenam entre si e se completam para a consecução do mesmo fim a que se propõem, qual seja, a realização do direito daquele que alega ser o seu titular.

A tutela direta configura-se individual, voluntariamente e espontânea praticada pelo sujeito obrigado ao cumprimento do dever ou da obriga- ção, seja este movido pela persuasão comum que reside no âmago de qualquer ser humano como pessoa correta e cumpridora de seus deveres, seja por exortação de princípios jurídicos gerais que militam em prol do cumprimento de relações jurídicas que se expandem por todo o contexto da lei civil.

Assim sendo, verifica-se no campo da tutela substancial "stricto sen$s u$ ”, como a primeira e originária solução para o cumprimento do dever ou da obrigação pelo obrigado, a tutela substancial direta, quando o obrigado ou sujeito passivo da relação jurídica material satisfaz o cumprimento do seu dever perante o titular do direito, e o faz voluntária e espontaneamente, seja influenciado por exortação e persuação de princípios jurídicos, que vingam na área obrigacional, na do direito de propriedade, na do direito de família e na do direito sucessório, tais como, respectivamente, o da força obrigatória dos contratos expressa no brocardo latino do "pacta sunt servanda”; o da cláusula penal (Cód. Civil, art. 410) o do cumprimento do dever de mútua assistência por ambos os cônjuges na relação matrimonial (Cód. Civil, art. 1.566, III); o da obrigação do mutuário de restituir ao mutuante o objeto mutuado, pelo modo e tempo ajustados (Cód. Civil, art. 590); o do respeito que todos os indivíduos e todas as entidades devem observar quanto ao direito do "dominus" (Cód. Civil, art. 1.228); o do 
cumprimento do dever de mútua assistência por ambos os cônjuges na relação de matrimônio (Cód. Civil, art. 1.566); o da obrigação dos sucessores de pagar as dívidas deixadas pelo "de cujus" (Cód. Civil, art. 1.997) etc. Ou, ainda, o obrigado ou sujeito passivo na relação material cumpre o dever ou a prestação ajustados com a outra parte, influenciado por princípios éticos que se formam espontânea e naturalmente na consciência do dever cumprido, qualidades pessoais de que, em regra, se comprazem e são constatadas na imensa maioria de seres humanos de correto modo de agir.

Destarte, o cumprimento do dever ou da prestação pelo obrigado por meio da tutela substancial direta "stricto sensu”, que se perfaz pela ação individual, natural e espontânea do obrigado, a atuação deste há de abranger amplitude capaz de satisfazer quantitava e qualitativamente o resultado do dever ou da prestação originalmente convencionados na relação jurídica material formada entre as partes. E tal abrangência se dá tanto no contexto do direito privado, quanto no do direito público, porquanto as limitações negociais que possam advir no terreno deste último, em decorrência de princípios de ordem pública que não têm influência no caso da tutela substancial direta, de vez que esta se realiza pela satisfação de um resultado ou bem jurídico já considerado e originariamente concebido, como se disse, na oportunidade em que tais exigências de ordem pública já foram consideradas e resolvidas. Observe-se ainda que a tutela substancial direta, na hipótese de interferência de princípios de ordem pública na relação privada, deve realizar-se exatamente no tempo e pelo modo convencionado ou estipulado na lei, no ato de sua constituição.

Coordenada com a primeira e originária tutela substancial direta, atua e convive com esta o outro tipo de tutela substancial, que se consubstancia na segunda forma de tutela substancial "stricto sensu", a tutela substancial indireta, que se realiza com o mesmo escopo da tutela substancial direta, apenas com a particularidade especial de que não se opera pelo cumprimento do dever ou da obrigação espontaneamente pelo obrigado.

Em tal hipótese, esta forma de tutela indireta opera-se não mais mediante o cumprimento individual e espontâneo do dever ou da prestação pelo obrigado, ajustados na relação jurídica material originariamente ajustada entre os dois sujeitos que a compõem, mas pelos modos de implemento indireto, que se realizam mediante um novo ajuste compositivo a ser negociado por meio da confluência de interesses das partes, que resta na dependência também da espontaneidade manifestada pelo obrigado ou sujeito passivo da dita relação jurídica e da conformidade e cooperação do sujeito titular do 
direito nessa oportunidade discutido, operando-se tal composição amigável exclusivamente no contex to do direito privado e disponível.

Deste modo, cumpre observarse que no procedimento da tutela substancial indireta o cumprimento do dever ou da obrigação, pelo obrigado, não se dá, como se disse, pela exclusiva iniciativa individual e pessoal deste, mas por outra modalidade de ajuste entre as partes, com participação e cooperação dúcteis do sujeito ativo, ou titular do direito, mediante as figuras do pagamento com sub-rogação convencional (Cód. Civil, art. 347); da dação em pagamento (Cód. Civil, art. 356); da novação Cód. Civil, art. 360); da transação extrajudicial (Cód. Civil, art. 840); da arbitragem (Lei no 9.307/96) etc.

Assim, essa segunda forma de tutela substancial "stricto sensu", que se produz de modo indireto, como substituta da anteriormente referida, é operada com o objetivo de compor o mesmo desígnio e surtir os mesmos efeitos da tutela direta, não pelo cumprimento do dever ou da obrigação "in natura", como na tutela direta, mas como sua substituta ou equivalente.

E tal atitude compositiva das partes só se torna operavelmente viável e possível no âmbito do direito privado, em que o objeto da relação for disponível, podendo os sujeitos intervenientes inovar outras soluções do ato ou negócio jurídico, no uso pleno de suas manfestações de vontade. À evidência, tal não pode ser factível, também, no complexo da tutela substancial direta realizada em relações de direito público, porquanto o influxo de ordem pública sobre a esfera privada já fora necessariamente observado no ato de constituição do negócio.

As tutelas substanciais "stricto sensu", nas suas formas direta e indireta, por que se operam, a primeira originariamente, mediante a atuação "in natura", individual e espontânea do cumprimento do dever ou da obrigação pelo obrigado e, na falta desta, por qualquer razão, a segunda é operada mediante a conjugação da espontaneidade do obrigado com a colaboração e cooperação dúctil do sujeito titular do direito, realizando-se esta por meio da chamada transação extrajudicial e demais meios desse gênero, de modo que ambas, pelo seu compartilhamento efetivo na tarefa da solução suasória da relação jurídica material, revestem-se da característica da coordenação entre si, que lhes advêm do complexo normativo-jurídico em que estão sediadas. E na visão filosófica em que é concebido o fenômeno jurídico, a relação intersubjetiva que nelas se contém, não é encarada somente pelo ângulo da dogmática, que se circunscreve ao exame puro e simples das pretensões e dos interesses contrapostos dos sujeitos e se satisfaz 
com uma análise linear e individuada de uma intersubjetividade que ora se projeta no polo ativo, ora no polo passivo, sem transcender a respectiva ordem de coordenação entre ambas.

$\mathrm{Na}$ dita visão filosófica, essa relação de coordenação que se transfunde em fenômeno jurídico transcendente às pessoas individuadas nelas intervenientes, no sentido de que as pretensões ou o bem da vida que lhes dá o conteúdo, não pertence exclusiva e individualmente nem ao sujeito ativo, que afirma ser o seu titular, nem exclusivamente ao sujeito passivo, na condição de submisso ao cumprimento do dever a que se atrelou, mas nelas se vislumbra um nexo intersubjetivo que atribui direitos e deveres recíprocos aos dois sujeitos que, compartilhadamente, um deles recebe o reconhecimento e a satisfação do seu direito e, o outro, a determinação do cumprimento do dever.

É preciso ter presente que a abrangência da relação jurídica disputada entre os sujeitos que nela intervêm, não decorre apenas de uma coordenação subjetiva entre si, mas de uma coordenação objetiva que transcende o "ego" e o "alter", envolvendo-os em um nexo comum, que possibilita a ambos manifestações de pretensões e deveres recíprocos, que os coloca diante de uma bilateralidade objetiva, que é específica para o fenômeno jurídico, segundo a autorizada doutrina filosófica de Miguel Reale, com fincada tradição no nosso meio jurídico ${ }^{15}$.

Este é o panorama em que se encarta a tutela substancial, revelador de uma coordenação recíproca entre as duas formas de tutela. A direta, em que o cumprimento do dever ou da obrigação, pelo obrigado, se dá individualmente por este, por efeito de sua espontaneidade pessoal como sujeito passivo interveniente na relação material e se opera sem a participação do sujeito ativo e titular do direito. Enquanto na tutela indireta, o cumprimento do ato ou negócio jurídico resta na dependência de um novo ajuste da relação jurídica originária geralmente proposto pelo sujeito passivo que a pretende alterada para satisfazê-la; para o que, torna-se necessária contar este com a cooperação dúctil do sujeito ativo, titular do direito, como já anteriormente referido, e opera-se essa coordenação recíproca entre as duas formas de tutela substancial mediante as figuras, entre outras, do pagamento com sub-rogação convencional, da dação em pa-

15 REALE, Miguel. Filosofia do Direito. V. II, n. 244, p. 584-585. São Paulo: Edição Saraiva, 1962. Sobre esse mesmo tema já havíamos tratado em artigo intitulado: "A bilateralidade atributiva do direito" (segundo a doutrina de Miguel Reale). In: Revista Forense, V. 331, p. 87-96, Editora Forense. 
gamento, da novação, da transação extrajudicial, quiçá, também da arbitragem, antes referidas. E, observe-se, tal coordenação recíproca entre essas duas modalidades da tutela resulta da bilateralidade e da reciprocidade de direitos e obrigações entre os intervenientes nas relações jurídicas que se encontram caracterizadas no sistema nacional, especificamente na teoria geral dos contratos, segundo a qual nenhum dos contratantes pode exigir a prestação do outro, se não cumpriu a sua, conferindo ao prejudicado a exceção substancial da "exceptio non adimpleti contractus".

Há, ainda, uma terceira forma de tutela substancial "lato sensu", que se consubstancia na chamada autotutela, por alguns autores, como Niceto Alcará-Zamora y Castillo, a denominam autodefensa" 16 e que por outros chamada "auto-ajuda" 17 , podendo ser aprioristicamente definida como o poder geral de defesa do próprio direito ou de direito alheio juridicamente reconhecido, a fim de mantê-lo inalterado e consolidado nos casos expressamente declarados na lei, em "numerus clausus" ${ }^{18}$. É, pois, a autotutela uma providência defensiva pré-processual, caracterizadamente unilateral, que o titular do direito subjetivo a exerceu individualmente, por vontade própria e com suas próprias forças, operando-a mediante o exercício da pretensão material no resguardo do seu direito ameaçado de descumprimento ou já descumprido pelo outro interveniente na relação jurídica, movida unilateralmente por determinação pessoal, sem prescindir da cooperação do contra-interessado. Como resulta da própria semântica do vocábulo, a autotutela constitui-se pela atuação do próprio titular do direito, com exclusão da participação de qualquer outra pessoa, entidade ou poder ${ }^{19}$.

Mas, na antiguidade, o uso da autotutela como instrumento de proteção dos direitos subjetivos pode ser considerado uma das primeiras providências concretas adotadas pelas sociedades antigas com tais objetivos. Isso acontecia notadamente em épocas anteriores à organização do Estado, quando essa atuação individual e egoística do sujeito de

16 ALCALÁ-ZAMORA Y CASTILlO, Niceto. Processo, Autocomposición y Autodefensa. p. 35 e segs. Textos Universitários. México: UNAM, 1970.

17 RADBRUCH, Gustavo. Introducción a la Filosofia del Derecho. Trad. Espanhola, p. 93. México: UNAM, 1951.

18 DAGNINO, Antônio. Contributo allo Studio Dell Autotutela Privata. p. 62-67; 306. Milano: Ed. Giuffrè, 1983.

19 BONGIORNO, Girolano. L'Autotutela Esecutiva. p. 3. Milano: Ed. Giuffrè, 1984. 
direito se realizava através da justiça de mão própria ou justiça privada. Porém, a partir do momento em que se passou a plasmar, no convívio dos povos, a organização da sociedade política e a estabelecer-se uma estrutura funcional do Estado, passou a autotutela a ceder espaço ao processo organizado e dirigido pelo Estado. Verificou-se, então, um processo de involução paulatina da autotutela em relação ao processo organizado, em razão do monopólio da jurisdição que o Estado de direito avoca a si, na atualidade, no tocante à solução dos litígios que se travam entre os membros da comunidade e que refogem das soluções contempladas na tutela substancial "stricto sensu".

No que diz com o seu objeto, a autotutela atua prevalentemente no campo do direito privado, eis que no âmbito do direito público torna-se difícil a sua operosidade, em face da indisponibilidade do bem jurídico objeto das relações que se travam nesse setor.

Assim, atuando na área privatista, a autotutela projeta-se como instrumento extrajudicial, caracterizadamente individual e unilateral, que o sistema jurídico confere ao sujeito de direito, em caráter especial, para a salvaguarda imediata do seu direito, naqueles casos em que, devido à demora ou à complexidade da tutela judicial, não se constitui esta no mais expedito e célere instrumento para oferecer proteção capaz de evitar agressão iminente a bem jurídico de que o sujeito é agente e titular, em determinado momento. Todavia, a atuação deste deve limitar-se estritamente aos atos indispensáveis para implementar a proteção necessária, como prescreve genericamente a nossa lei civil, porque, se tais atos ultrapassarem o indispensável à preservação do direito ameaçado, o agente incorrerá em abuso de direito, vedado na ordem civil (C. Civil, art. 187).

Assim, figuram como exemplos típicos de autotutela, no âmbito do direito privado brasileiro, entre outros, o desforço possessório previsto no artigo 1.210 e $\S 1^{\circ}$, da vigente codificação civil de 2002, bem como o exercício de direito de retenção por benfeitorias necessárias e úteis, autorizado no artigo 1.516 da mesma codificação vigente de 2002 , em favor do possuidor de boa-fé.

Além da proteção dos direitos próprios dos sujeitos de direito, poderá, ainda no âmbito do direito privado, ser a autotutela utilizada para a proteção de direitos alheios, por quem estiver investido de poder legítimo para defendê-los. Os exemplos mais frutificantes desses direitos residem no poder familiar, que aos pais compete exercer em relação à pessoa e aos bens dos filhos (C. Civil, art. 1.689, incisos I e II), bem como na tutela de menores e na curatela, quando ao tutor e ao curador compete exercer a 
direção da pessoa e a administração dos bens de tutelados e curatelados (C. Civil, arts. 1.741 e 1.774). Também podem ser incluídos nessa escala de proteção pela autotutela os direitos do nascituro, que à mãe, no caso de falecimento do pai, compete exercer (C. Civil, arts. $2^{\circ}$ e 1.779).

Ainda que as hipóteses supra versadas sejam habitualmente catalogadas e sediadas em setores do direito privado, na verdade nelas se contêm interesses de ordem pública, limitativos da manifestação da autonomia de vontade dos sujeitos que os representam, eis que em seus conteúdos estão balizados pela indisponibilidade.

Demais disso, ainda que não constitua objeto deste trabalho, que se situa no contexto da tutela substancial, atuante na área privatista, não é demasia lembrar-se que a autotutela também atua, com maior largueza, no terreno do direito público, notadamente no direito administrativo, sede em que é definida pelos tratadistas da área como "o conjunto de normas de direito público que rege a ação administrativa, dirigida à vigilância dos próprios atos, e manifestada através do poder de polícia”.
Observa Cretella Junior que, mediante a autotutela, o ato administrativo editado e eficaz, ora pode ser desfeito, ora recuperado, nas cinco hipóteses clássicas consubstanciadas na anulação, revogação, ratificação, reforma e conversão ${ }^{20}$.

Há que se salientar que, enquanto na área privada a autotutela é exceção que só ocorre nas hipóteses admitidas na lei, no âmbito do direito administrativo ela é a regra, constituindo-se em atividade contínua e incessante, como mecanismo de proteção dos atos administrativos e dos bens públicos. Como salientam os administrativistas, a autotutela na administração "erige-se em figura ou princípio típico de direito administrativo, sem símile nos outros ramos da ciência jurídica, a não ser por exceção"21.

Ainda na esfera do direito público, especificamente na área penal, configura-se como instrumento de autotutela do praticante do delito o ato de legítima defesa, definido e delimitado no artigo 25 do Código Penal, setor em que sua ocorrência se torna mais relevante, por referir-se à integridade corporal ou à própria vida humana. Situação paralela verifica-se

20 CRETELLA JUNIOR, José. Dos Atos Administrativos Especiais. n. 53, p. 106-108. Rio de Janeiro: Edição Forense, 1995.

21 Sobre o tema ver: CRETELLA JUNIOR, José. Da autotutela administrativa. In: Revista de Direito Administrativo, V. 108, p. 48-49, abril/junho 1972, impressão nos Estabelecimentos Gráficos Borsoi S.A. Rio de Janeiro: Edição Getúlio Vargas, 1972. 
também, quando o agente pratica o fato em estado de necessidade, cujos limites encontram-se definidos no artigo 24 da codificação penal.

\section{AS VIAS INSTRUMENTAIS DE TUTELA JUDICIAL}

Embora o tema deste trabalho doutrinário tenha sido examinado precipuamente no campo do sistema substancial de tutela, não se poderá deixar de analisar, ainda que em apertada síntese, como se fez no capítulo 2, supra, a operalidade procedimental da tutela judicial. E agora se faz pela razão evidente de que o sistema substancial de tutela, que se realiza pelos canais da tutela direta e da indireta, mediante o cumprimento espontâneo do dever ou da obrigação, pelo obrigado, na primeira hipótese, ou através da negociação com o titular do direito, na segunda, não esgota a plenitude da proteção necessária aos direitos dos cidadãos no sistema jurídico brasileiro. E assim é, porque é sabido que a sociedade não se compõe inteiramente por seres humanos corretos, responsáveis e cumpridores dos seus deveres, ainda que estes representem a imensa maioria dos cidadãos, todavia, não é ignorada a existência de certo contingente social de indivíduos que, por razões as mais variadas, se omitem ou se esquivam de cumprir seus deveres perante o "alter", caso em que a solução das relações jurídi- cas, só se torna factível por meio da tutela judicial, mediante a atuação coercitiva do Estado-juiz, pela via do processo jurisdicional.

A tutela judicial, que se configura substitutiva, derivada e consequencial, em face da inocorrência dos canais da tutela substancial, é classificada pela doutrina tradicional e majoritária em tutela de cognição ou de declaração, tutela de execução ou de cumprimento de sentença e tutela cautelar, subdividindo-se esta, a primeira, nos três tipos clássicos, pertinentes ao processo de cognição, em tutela meramente declaratória, constitutiva e condenatória, havendo processualistas que divergem dessa classificação e a ela acrescentam a tutela mandamental e a tutela executiva "lato sensu".

Quanto à sua amplitude, há que se situar a tutela judicial em conformidade com a pretensão (de direito material) formulada no pedido, pelo autor, que se invoca titular do direito descumprido pelo obrigado, como refere a tradicional parêmia "sententia debet esse conformis libelo". Verifica-se, assim, quanto à amplitude da tutela judicial, fenômeno paralelo ao que ocorre com a tutela substancial "stricto sensu", cuja abrangência há de bastar qualitativa e quantitativamente o resultado, ou o bem da vida, originalmente convencionado pelas partes ou estipulado na lei, no ato de formação da relação ou situação jurídica tutelada. 


\section{REFERÊNCIAS}

ALCALA-ZAMORA Y CASTILLO,

Niceto. Processo, Autoconposicion y Autodefensa. p. 35 e segs. Textos Universitários. México: UNAM, 1970.

ANTUNES, Luis Felipe Colaço. $A$ Tutela dos Interesses Difusos em Direito Administrativo. p. 5561. Coimbra: Editora Almedina, 1989.

BOBBIO, Norberto. Bobbio e a Filosofia dos Juristas. Porto Alegre: Sérgio Antonio Fabris Editor, 1994.

BONAVIDES, Paulo. Curso de Direito Constitucional. p. 571-572. São Paulo: Edição Malheiros, 2009.

BONGIORNO, Girolano. L'Autotula Esecutiva. p. 3. Milano: Ed. Giuffrè, 1984.

BRASIL. Constituição Federal de 1988. A função Social das propriedades urbana e rústica. Título VII, Capítulos II e III, artigos 182-191.

CRETELLA JUNIOR, José. Dos Atos Administrativos Especiais. n. 53, p. 106-108. Rio de Janeiro: Edição Forense, 1995.

. Da Autotutela administrativa. In: Revista de Direito Administrativo. v. 108. p. 48-49. Abril-junho 1972. Rio de Janeiro: Edição da Fundação Getúlio Vargas, Ed. Estabelecimentos Gráficos Borsoi, 1972.
DAGNINO, Antonio. Contributo allo studio dell'Autotutela Privata. p. 3-6; 62-67, Milano: Ed. Giuffrè, 1983.

DEL VECCHIO, Giorgio. Lições de Filosofia do Direito. Trad. Portuguesa de Antonio José Brandão. p. 353. Coimbra: Armenio Amado Editor, 1979.

DI MAJO, Adolfo. La Tutela Civile dei Diritti. p. 57-58. Milano: Ed. Giuffrè, 1987. . La Tutela dei Diritti. p. 4-10. Milano: Ed. Giuffrè, 1987.

DINAMARCO, Cândido Rangel. Tutela jurisdicional. In: Separata da Revista Forense. V. 334, p. 25. Rio de Janeiro: Ed. Forense.

ESPANHA. Constituição de 1978. Artigo 33, Edição Oficial.

FARIA, Ernesto (Professor). Dicionário Escolar Latino-Português. p. 1.028-1.029, 4. ed. Publicação do Departamento Nacional de Educação do Ministério da Educação, Rio de Janeiro, 1967.

FERRAZ, Ana Cândida; GRINOVER, Ada Pellegrini. Liberdades Públicas, São Paulo: Edição Saraiva, 1978.

FERREIRA FILHO, Manuel Gonçalves. Liberdades Públicas. p. 45-72. São Paulo: Edição Saraiva, 1978.

FRANÇA. Declaração dos Direitos do Homem e do Cidadão. Artigo 
$17^{\circ}$. Incorporada ao preâmbulo da Constituição de 1946 e ratificada pelo Estatuto de 1958.

FRANCO, João Melo; MARTINS, Herlander Antunes. Conceitos e Princípios Jurídicos. p. 403. Coimbra: Edição Livraria Almedina, 1983.

GOMES, Orlando. Introdução ao Direito Civil. n. 73, p. 142-144. Rio de Janeiro: Edição Forense, 1979. ITÁllA. Constituição de 1958. Artigo 42, Edição Oficial.

. Codice Civile e Leggi Collegate. Libro Sesto, Della Tutela dei Diritti. p. 446-491. Bologna: Ed. Zanichelli, 2007.

NORONHA, Carlos Silveira. Liberdades Públicas. Uma breve visão político filosófica. In: Revista Forense. V. 328, p. 31-36, outubro-novembro-dezembro de 1994, Rio de Janeiro, Cia. Editora Forense.

NORONHA, Carlos Silveira. A bilateralidade atributiva do direito (segundo a teoria de Miguel Reale). In: Revista Forense. V. 331, p. 87-96, julho-agosto-setembro/ 1995, Rio de Janeiro.

OLIVEIRA JUNIOR, José Alcebiades de. Estado e Eficácia dos Direitos Fundamentais. In: Revista do Direito da UNISC. n. 11, p. 52. Santa Cruz do Sul, 1999.

PASSOS, Calmon de. A posição deste autor, contrária à distinção entre "direito" e "interesse" é extensiva aos chamados "interesses transindividuais". Sobre tal distinção CALMON DE PASSOS, ainda se manifesta: "A dualidade de terminologia (interesses no transinvidual; direito, no individual) é de todo desautorizada, apenas traduzindo o remanescente conservador (mesmo inconsciente) dos que ainda não lograram se libertar da estreita cela em que foi aprisionada a noção clássica de direito subjetivo". CALMON DE PASSOS, J. J. In: Mandado de Segurança Coletivo, Mandado de Injunção, Habeas Data. p. 10-11. Rio de Janeiro: Edição Forense, 1989.

PELLOUX, Robert. Vrais et Faux de 1'Homme - Problèmes de Definition et de Classification. In: Revue der Science Politique em France et à l'Étranger. n. I, p. 54 et note 8.

PONTES DE MIRANDA, Francisco Cavalcante. Comentários ao Código de Processo Civil de 1973. Tomo I, p. 100. Rio de Janeiro: Edição Forense, 1974.

PORTUGAL. Constituição de 1976. Artigo 62, Edição Oficial.

RADRUCH, Gustavo. Introducción a la Filosofia del Derecho. Trad. Espanhola, p. 93. México: Ed. UNAM, 1951.

REALE, Miguel. Filosofia do Direito. V. II, n. 244, p. 584-585. São Paulo: Edição Saraiva, 1962. 